\title{
$\underline{056}$
}

\section{Investigation of trace metals in air particulate matter collected from Colombo}

\author{
A D T Liyanage ${ }^{1}$, K G S Jayawardana², R N R Jayaratne ${ }^{2}$, C K Amaratunga² and K R R Mahanama' \\ 'Department of Chemistry, University of Colombo, Sri Lanka. \\ ${ }^{2}$ Central Environmental Authority, Battaramulla, Sri Lanka.
}

The suspended particulate matter (SPM) in air is a complex multi-phase mixture of all airborne chemicals. Among the airborne inorganic chemicals, compounds associated with heavy metals have subjected to numerous chemical investigations due their known health effects. Uniqueness of the heavy metals has attributed its use in identifying or tracing the pollutant sources through source apportionment studies and in understanding the distribution of pollutants through computer modeling.

In general, airborne metals exist in trace quantities. The suspended particulate matter may contain the metallic species as fine particles or they may have adsorbed onto other particulate matter originated from natural or human activities. Agglomerated heavier particle settles due to gravitation and pose a lesser risk to human health. Finer particles with aerodynamic diameter less than $2.5 \mu \mathrm{m}\left(\mathrm{PM}_{25}\right)$ are believed to posses the biggest health threat through respiration.

Central Environmental Authority (CEA) has been involved in air quality monitoring at the Colombo Fort Railway Station. Using their high volume air sampler, particles having aerodynamic diameter less than $10 \mu \mathrm{m}\left(\mathrm{PM}_{1}\right)$ were collected onto glass fiber filters daily during the period of November 2003 to November 2005 November. They were gravimetrically analyzed by CEA. This study was focused to further investigate randomly selected filters (two filters per month) to differentiate the levels of selected metals during the period. The filters were acid digested to recover the airborne metallic species. Levels of copper $(\mathrm{Cu})$, nickel $(\mathrm{Ni})$, cadmium $(\mathrm{Cd})$, lead $(\mathrm{Pb})$ and manganese $(\mathrm{Mn})$ were analyzed by using atomic absorption spectrophotometer at the Department of Chemistry, University of Colombo.

The average concentrations found during the study were $\mathrm{Cu}=0.29 \pm 0.25 \mathrm{ng} / \mathrm{m}^{3}, \mathrm{Ni}=0.21 \pm 0.10 \mathrm{ng} /$ $\mathrm{m}^{3}, \mathrm{~Pb}=0.59 \pm 0.48 \mathrm{ng} / \mathrm{m}^{3}, \mathrm{Cd}=0.03 \pm 0.03 \mathrm{ng} / \mathrm{m}^{3}, \mathrm{Mn}=0.43 \pm 0.22 \mathrm{ng} / \mathrm{m}^{3}$. During the study period $\mathrm{Pb}$ levels were found to be the highest and $\mathrm{Cd}$ levels were found to be the lowest. The maximum airborne levels were $1.24 \mathrm{ng} / \mathrm{m}^{3}$ for $\mathrm{Cu}$ in April 2005, $0.56 \mathrm{ng} / \mathrm{m}^{3}$ for $\mathrm{Ni}$ in January $2005,2.37 \mathrm{ng} / \mathrm{m}^{3}$ for $\mathrm{Pb}$ in February 2004, $0.09 \mathrm{ng} / \mathrm{m}^{3}$ for Cd in February 2004 and $0.78 \mathrm{ng} / \mathrm{m}^{3}$ for Ni in May 2005.

On average the minimum airborne levels were found in the period of May to August. This is attributed to the settling of particles with rainfall as well as the wind patterns which drifts the pollutants away from the sampler during the season. From November to April all the five metals have showed relatively higher concentrations compared to any other months in each year. This may be due to poor dispersion patterns in the Colombo air which results in stagnating pollutants. In general, wind speed is relatively higher for the period of May to August compared to the period of November to April.

The most prevailing metal in the Colombo air is $\mathrm{Pb}$ while the least prevailing metal is $\mathrm{Cd}$. The levels of $\mathrm{Pb}$ have demonstrated a pronounced decline in concentration starting from April 2005 which coincides with the introductior of un-leaded petrol to Sri Lankan market in January 2004.

\section{7}

\section{Factors governing an integrated solid waste management program: A case study at Nuwara-Eliya district secretariat division}

\author{
A G Amarananda and N J G J Bandara \\ Department of Forestry and Environmental Science, University of Sri Jayewardenepura, Sri Lanka
}

Solid Waste Management is one of the main national problems in Sri Lanka and integrated solid waste management (ISWM) has been recommended as the only solution. However, ISWM is hardly successfully practiced anywhere in the country due to many inherent reasons. This study examines the governing factors for the success/failure of an ISWM program within 3 LAs including Municipal Council (MC), Urban Council (UC), and Pradeshiya sabha (PS) in Nuwara Eliya Divisional secretary

Proceedings of the International Forestry and Environment Symposium 2006 of the 
area. The main objectives of this study were to identify these governing factors and ways to overcome constraints in implementing a IWMS successfully in the country.

For this case study 135 households (HH) representing high, medium, and low income categories were selected from 3 LAs in the DS and field surveys were conducted for a period of three months. These households were given 3 bags of different colors once a week and householders were requested to separate the waste into different types and collect separately once a week. Waste collected on the other days was given to the municipal collectors. This sorted waste was measured to assess participation. The willingness to engage in an ISWM program was gauged through questionnaire surveys asking for their willingness and also by actually monitoring their continuous participation in the solid waste sorting exercise throughout the study period. A second questionnaire survey was conducted on the same group of people to assess whether their response has changed after actually engaging in the ISWM exercise. In addition surveys were also conducted to assess the Duties and Responsibilities of LAs with regard to SWM, Practices of 3R (Reduce, Recycle, Re-use) systems by LAs and HHs, final disposal mechanisms and Public awareness and attitudes towards issues related to SWM etc. Interviews were held with LA officials also for these information. The study revealed that the dominant SWM problems in the LAs are, lack of suitable land for final disposal, lack of public participation and cooperation, among others.

The questionnaire survey conducted at the beginning of the study revealed that willingness to sort out SW was found to be $98.33 \%$. However after the three month period it was found that only $86.6 \%$ have participated in the actual sorting out and the second survey has shown the response to be $87.39 \%$ for willingness to sort. At the beginning willingness to Re-use or Recycle of SW was $77.69 \%$. Statistical analysis showed that this factor is related to the chief occupants educational level, Income and the service provided by LAs. $53.3 \%$ participants have indicated willingness to compost if a compost bin is provided whereas only $19.17 \%$ have indicated willingness to compost if a bin is not provided. In addition it was revealed that only $28.7 \%$ of the participants are willing to make an additional payment for a better service and only 52.63 are willing to assist the local authority resolve SW problems in the LA. The waste generation quantity data which were statistically analyzed showed that waste generation depends significantly on the income levels and the locality. According to the results it can be concluded that ISWM involves a wide variety of tasks, involving both individual and team work. Since factors such as education level, income level also govern participation in an ISWM program a common practice cannot be targeted for all. Specific programs should be developed for different neighborhoods and targeted awareness creation is compulsory.

\title{
$\underline{058}$ \\ Lichens as biomonitors of sulphur dioxide and nitrogen dioxide pollution in Colombo and suburbs
}

\author{
A M N P Attanayaka and S C Wijeyaratne \\ Department of Botany, University of Sri Jayewardenepura, Sri Lanka
}

Biological monitoring is an efficient and inexpensive method for monitoring air quality. Studies have confirmed that lichens are among the most reliable accumulators of airborne inorganic contaminants. As limited research has been done in tropics with regard to biological monitoring, a study was carried out to monitor lichen diversity and distribution in selected locations in Colombo and its suburbs.

Thirty one sites located on six radial transects diverging from Colombo Fort were selected for this study. Eight trees from three trees species, (Cocos nucifera, Mangifera indica, and Artocarpus heterophy/lus $)$ within each site $\left(1 \mathrm{~km}^{2}\right)$ were chosen for the study. Coverage and frequency of corticolous all lichens found on selected trees were recorded by using $250 \mathrm{~cm}^{2}$ grids. After studying their morphology, anatomy, reproductive structures and chemistry, lichens collected were identified using keys. In addition, land use pattern, traffic density, $\mathrm{pH}$ of substrates, exposure levels of these sites to light were also recorded. Ambient $\mathrm{SO}_{2}$ and $\mathrm{NO}_{2}$ levels at each site were determined using passive samplers having filter pads coated with the absorbing reagents, ethylene glycol and acetone, for $\mathrm{SO}$, and $\mathrm{Nal}, \mathrm{NaOH}$ and Ethylene glycol for $\mathrm{NO}_{\text {. }}$. Data were statistically analyzed by using the mean comparison, correlation and by principal component analysis to investigate relationship between diversity of lichens and environmental parameters.

Proceedings of the International Forestry and Environment Symposium 2006 of the

Department of Forestry and Environmental Science, University of Sri Jayewardenepura. Sri Lanka 